\title{
AVALIAÇÃO, MERITOCRACIA E PERFORMATIVIDADE: UMA ANÁLISE DA POLÍTICA EDUCACIONAL PERNAMBUCANA
}

\author{
Sergio Andrade Moura \\ Angela Maria Dias Fernandes ${ }^{(*)}$
}

Desde a década de 1990, vem acontecendo, de forma bastante intensa, acalorados debates e movimentos voltados para a difusão de discursos e concepções, em nível mundial. Neles estão envolvidos inúmeros atores e organizações, abordando o imperativo de se realizarem reformas educacionais e de se encontrarem soluções para os problemas da educação pública.

Essas reformas, desde o seu início, apresentaram-se intimamente relacionadas com uma espécie de "consenso" que se formava nesses círculos de debates a respeito do novo modelo de política educacional pautado nos princípios gerenciais e neoliberais. A partir desse movimento efetivaram-se reformas educacionais em um grande número de nações (BALL; MAGUIRE; BRAUN, 2016).

Em um potente contexto de influência (BOWE; BALL; GOLD, 1992), em que operavam as forças neoliberais, tal discurso da reforma gerencial na gestão pública, bem como na educação, era difundido e defendido com veemência. No Brasil esse modelo encontrou solo fértil e começou a ser implementado nos governos de Fernando Henrique Cardoso (FHC) (1995-1998/1999-2002). Para os atores que compunham e sustentavam o governo de presidente FHC, era imperioso promover, por meio da reforma gerencial, a modernização do aparelho do Estado para se assegurar a competitividade na nova realidade global. Buscava-se com a reforma gerencial promover a eficiência administrativa e financeira da ação estatal, importando para a esfera pública a lógica do privado, pautada na responsabilização, na avaliação de desempenho, no controle dos resultados e na criação dos quase-mercados. Nesse contexto, o Estado deixa de ser o provedor direto das políticas públicas para assumir, dentro do novo arranjo de autonomia e descentralização, sobretudo, os poderes de regulação dos entes subnacionais, das agências e dos servidores públicos (BRESSERPEREIRA, 2002; BRESSER-PEREIRA; SPINK, 2006). Quase simultaneamente à reforma gerencial na administração pública, iniciada nos governos de FHC, foi orquestrada a reforma

\footnotetext{
${ }^{(*)}$ Sergio A. Moura. Mestre em Educação pelo Programa de Pós-Graduação em Educação da UFPB (2017). Membro do Grupo de Pesquisa - Psicologia Educacional, formação e infância - estudos sobre classes populares e educação pública PEFI (UFPB/PPGE).

Angela Maria D. Fernandes. Professora aposentada colaboradora (Associada IV) do Departamento de Psicologia, docente credenciada do Programa de Pós-Graduação em Educação da Universidade Federal da Paraíba.
} 
educacional que sofreu diretamente as suas poderosas repercussões e passou a funcionar de acordo com sua lógica gerencial e com os princípios do mercado.

Especificamente em Pernambuco, território para onde se volta este estudo, tal processo é iniciado nos governos de Jarbas Vasconcelos (1999-2002/2003-2006) e afirmado nos governos de Eduardo Campos (2007-2010/2011-2014). O processo de implantação do Modelo de Gestão Todos por Pernambuco desde ano de 2007 tem significado a concretização e a intensificação de um movimento de reforma gerencial da administração, assim como repercutido na educação e na configuração de uma política educacional que articula múltiplas tecnologias gerenciais de controle e regulação.

Neste texto, analisa-se a política educacional adotada no Modelo de Gestão Todos por Pernambuco, considerando-se, especialmente, a política de avaliação de desempenho educacional implementada. A investigação desenvolve-se por meio de pesquisa bibliográfica e documental e apoia-se no referencial teórico-metodológico da Abordagem do Ciclo de Políticas (BOWE; BALL; GOLD, 1992).

Apresentam-se neste texto o processo de construção do Modelo de Gestão Todos por Pernambuco e as suas principais tecnologias gerenciais de controle, que procuram relacionar planejamento, execução e análise de resultados para alcançar a eficiência. Evidenciam-se, também, algumas das repercussões desse modelo nas políticas educacionais por meio do emprego de novas formas de gerir e avaliar que eliminam da cena escolar os principais sujeitos. Nesse processo a autonomia dos atores do campo da educação é ferida, e a responsabilização recebe realce, conforme se pretende demonstrar.

\section{NEOLIBERALISMO E GERENCIALISMO - INSPIRAÇÕES NA CONSTRUÇÃO DE UM MODO DE GOVERNAR}

Durante as gestões de Jarbas Vasconcelos, o modelo neoliberal de Estado mínimo foi adotado, e constatam-se um encolhimento da estrutura estatal com a redução do número de secretarias de vinte para treze, a extinção de dezoito órgãos da administração estadual, a eliminação de aproximadamente quarenta mil cargos efetivos e de cerca de dois mil comissionados e, finalmente, a privatização de diversas empresas estatais pernambucanas (MARINI; MARTINS, 2014). Nesse sentido, os atores que se congregaram em torno de uma crítica ao modelo de gestão marcado pelo neoliberalismo ortodoxo, encabeçados por Eduardo Campos, formularam o Programa de Governo da Frente Popular de Pernambuco: um novo Pernambuco (PSB, 2006), no qual 
expunham publicamente suas críticas. Acusavam o governo de focar, principalmente, questões de privatização e de ajuste fiscal, o que tinha produzido a redução do aparato estatal e, consequentemente, das políticas públicas sociais. Assim, os atores que se reuniam em torno desse programa defendiam a extinção do modelo vigente e a implantação de um novo modelo de gestão focado no planejamento estratégico, na gestão orçamentária e na busca de eficiência e resultados com a utilização intensa das tecnologias gerenciais, bem como de um novo modelo político e econômico que apresentasse uma confluência com os parâmetros propostos pela Terceira Via.

Nesse contexto, com a ascensão de Eduardo Campos ao governo estadual, no ano de 2007, juntamente com as forças que compunham a Frente Popular de Pernambuco, o neoliberalismo de Terceira Via e o gerencialismo encontraram um espaço privilegiado para sua consolidação.

A Terceira Via constituiu um movimento revisionista do modelo de neoliberalismo ortodoxo. Impulsionada na década de 1990, a Terceira Via buscou construir um programa político e econômico que fosse capaz de encontrar um ponto de equilíbrio entre o Estado, o mercado e a sociedade civil, em que o Estado fosse forte e eficiente o bastante para desenvolver a ação governamental de promover a justiça social pela emancipação do indivíduo. Buscava-se estabelecer um novo pacto social, que possibilitasse uma melhor administração dos conflitos de classe, conciliando a economia de mercado com ações no âmbito social, mas sem submeter o mercado à sociedade civil (GIDDENS, 2005). Além disso, a Terceira Via defendia o estabelecimento de um Estado gerencial, eficiente e focado em resultados. De acordo com Ball (2005), o gerencialismo é uma potente tecnologia política, governamental e de gestão, extremamente empregada nas reformas do aparelho do Estado. Por meio dessa tecnologia, busca-se introduzir a lógica empresarial e de mercado no âmbito público. O gerencialismo quando implementado estimula o monitoramento, a avaliação, a competição e a responsabilização das instituições e servidores públicos pelos serviços prestados à sociedade.

Em alinhamento com a perspectiva de "Governança para Resultados" (MARINI; MARTINS, 2014), elaborou-se em 2007 um projeto de reestruturação da gestão pública pernambucana, guiado pelos princípios gerenciais adotados pelo mercado. Esse projeto coadunava com as posições pregadas no projeto da Terceira Via e, segundo o Programa de Governo da Frente Popular de Pernambuco: um novo Pernambuco (PSB, 2006), procurava preparar o Estado para extrair benefícios do ciclo econômico experimentado pelo país naquele momento histórico. Nesse contexto, foi elaborado o Modelo de Gestão Todos por Pernambuco (2007), que norteou gestão de Eduardo Campos. 
Conforme apontam Marini e Martins (2014, p. 5), o Modelo de Gestão Todos por Pernambuco é um "Modelo de Governança para Resultados" e envolve, segundo esses autores, a atuação de diversos atores, como o Estado, o mercado e o terceiro setor, no planejamento e implementação das políticas públicas. Esse modelo de gestão do público envolvendo um arranjo com múltiplos atores apresenta uma perspectiva que converge para o neoliberalismo de Terceira Via (GIDDENS, 2005).

Um dos primeiros movimentos para construção do Modelo de Gestão Todos por Pernambuco foi a realização de um processo de Benchmarking ${ }^{1}$ em inúmeras instituições que atuavam, principalmente, na iniciativa privada e que operavam com processo de gestão e organização gerencial em busca de maior eficiência e eficácia para elevar o nível de desempenho no mercado competitivo (MARINI; MARTINS, 2014).

O Modelo de Gestão Todos por Pernambuco foi concebido para funcionar com várias tecnologias gerenciais que foram selecionadas dentre as mais adotadas pelas empresas privadas de acordo com os padrões do Controle da Qualidade Total (TQC). Dentre essas tecnologias destaca-se o Ciclo PDCA (Plan, Do, Check, Action). A tecnologia do Ciclo PDCA implanta no cotidiano das empresas um ciclo ininterrupto de planejamento e formulação (Plan), execução, desenvolvimento e monitoramento (Do), avaliação e controle (Check) e, finalmente, de ação corretiva e replanejamento (Action) (CRUZ, MARINI; LEMOS, 2014). Essa tecnologia funciona de modo a organizar e controlar todos os processos e rotinas empresariais a fim de maximizar as performances e, consequentemente, assegurar a eficiência e a eficácia dos resultados (CAMPOS, 2004; WERKEMA, 1995). Empregaram-se ainda outras tecnologias que subsidiaram o funcionamento do gerencialismo no Modelo de Gestão Todos por Pernambuco, como tecnologias para organizar planos de ação de metas prioritárias, processo de planejamento, execução, análise e revisão de projetos e definição de metas e estratégias com base em indicadores ${ }^{2}$ (CRUZ, MARINI; LEMOS, 2014).

Por meio de um instrumento jurídico-legal, a Lei Complementar n. 141, de 03 de setembro de 2009, o Modelo de Gestão Todos por Pernambuco foi institucionalizado e internalizado em todas as áreas de atuação da administração pública pernambucana (CRUZ, MARINI; LEMOS, 2014). O

\footnotetext{
${ }^{1} \mathrm{O}$ Benchmarking constitui-se em um processo sistemático voltado para analisar organizações que são reconhecidas em seus campos de atuação por adotarem os melhores métodos e práticas para alcançarem eficiência e resultados, bem como para se posicionarem competitivamente no mercado (SPENDOLINI, 1993).

${ }^{2}$ Dentre essas tecnologias pode-se citar a ferramenta 5W2H, a Ferramenta do Marco-Lógico ou Logical Framework e o Balance Scorecard (BSC) (CRUZ, MARINI; LEMOS, 2014).
} 
movimento de institucionalização desse modelo de gestão gerencial, com o emprego dessas inúmeras tecnologias amplamente difundidas e utilizadas na esfera privada, repercutiu na educação pública pernambucana, conforme será detalhado a seguir.

\section{REPERCUSSÕES NA POLÍTICA EDUCACIONAL - GERENCIALISMO E PRIVATIZAÇÃO NA HISTÓRIA ESCOLAR DE PERNAMBUCO}

A política educacional do Modelo de Gestão Todos por Pernambuco refletiu as diretrizes gerenciais e neoliberais que permearam esse modelo de gestão. Considerando a relação simbiótica entre contexto de influência e o contexto de produção de texto, conforme assinalam Bowe, Ball e Gold (1992), é patente no cenário das políticas educacionais pernambucanas a partir do ano de 2007 um movimento consistente voltado para construção de um forte aparato jurídico-legal e de discursos que buscavam legitimar e estabelecer o gerencialismo nas políticas educacionais, assim como contribuir no processo de rotinização dos rigorosos procedimentos de controle, monitoramento, avaliação de desempenho e de responsabilização em nome da eficiência gerencial.

Entre as muitas ações que promoveram o gerencialismo e a privatização da educação pública pernambucana a partir de 2008, ano em que tais ações estavam embasadas numa lógica empresarial, encontra-se a implementação da política de avaliação de desempenho, fundamentada na responsabilização, na meritocracia e na performatividade. Nessa política são empregadas diversas tecnologias que funcionam de modo articulado, integrados e em sintonia para produzir uma "boa educação" segundo os critérios gerenciais de resultados quantificáveis.

\subsection{Estado Avaliador e o avanço das "novidades globalizantes” em Pernambuco}

Norteada pela lógica gerencial, a política de avaliação de desempenho na educação pernambucana se afirma sob a égide do Modelo de Gestão Todos por Pernambuco. Constitui-se em uma política condizente com a perspectiva de Estado Avaliador (AFONSO, 2000) e fundamenta-se em processos de avaliação como mecanismos centrais para o controle dos resultados. Essa política educacional é complexa e envolve inúmeras tecnologias que funcionam com profundas interconexões. Dentre as tecnologias utilizadas nesse processo podem ser citadas: o Pacto pela Educação, o Sistema de Avaliação Educacional de Pernambuco (SAEPE), o Índice de Desenvolvimento da Educação de Pernambuco (IDEPE), o Termo de Compromisso e Responsabilização ou, como denominado na Lei 13.486, de 1 de julho de 2008 (PERNAMBUCO, 2008c), Termo de Compromisso de Gestão Escolar, a divulgação pública anual dos resultados das escolas no SAEPE/IDEPE e o Bônus de Desempenho Educacional (BDE). 
Ball, Maguire e Braun (2016) afirmam que existe uma forte pressão para elevar os padrões, alcançar as metas e apresentar resultados, que é exercida sobre as redes e instituições de ensino, por parte dos governos nacionais e subnacionais. Além disso, Ball (2014) procura destacar que entre as principais diretrizes das tendências das políticas educacionais globais encontra-se a introdução do gerencialismo na educação pública. Nesse sentido, o Modelo de Gestão Todos por Pernambuco, em sua perspectiva gerencial de busca de eficiência e eficácia, com foco em apresentar resultados e melhorar indicadores, adotou no campo das políticas sociais o Pacto pela Educação, o Pacto pela Saúde e o Pacto pela Vida. Esses pactos foram estruturados segundo a perspectiva gerencial para “[...] supervisionar, controlar e avaliar o modelo de gestão por resultados nessas áreas" (PERNAMBUCO, 2016a, p. 14), e suas diretrizes foram estabelecidas pelo Decreto n. 39.336, de 25 de abril de 2013 (PERNAMBUCO, 2013). O Pacto pela Educação converge para a defesa da adoção do gerencialismo na educação visando elevar a eficiência e apresentar resultados mensuráveis, pois consiste em uma poderosa tecnologia de monitoramento, avaliação e regulação, empregada no âmbito da educação em Pernambuco.

A partir do Decreto n. 39.336/2013 foi iniciada

[...] uma rotina de acompanhamento mensal de metas e planos estabelecidos para todos os anos do Ensino Médio [...] através de uma sistemática de monitoramento com o uso do Painel de Avaliação de Resultados (PERNAMBUCO, 2014, p. 13).

Além disso, visando abastecer o Pacto pela Educação com dados e informações, foi desenvolvido pela empresa Auge Tecnologia \& Sistemas LTDA e regulamentado pela Portaria SE n. 4.636, de 05 de junho de 2011 (PERNAMBUCO, 2011b), o Sistema de Informações Educacionais de Pernambuco (SIEPE). Segundo assinala Andrade (2014, p. 29), o SIEPE “[...] tornou-se uma ferramenta chave para o gerenciamento, acompanhamento e monitoramento do cotidiano escolar, proporcionando agilidade na tomada de decisão e correção de rota, quando necessário".

O Pacto pela Educação emprega em seus processos de monitoramento gerencial inúmeros indicadores que, em conjunto, abrangem o acompanhamento das atividades dos diversos atores da comunidade escolar, como professores (frequência, as aulas dadas e o cumprimento de conteúdos programados), estudantes (frequência escolar, os resultados no SAEPE/avaliação externa e os resultados nas avaliações da aprendizagem/avaliação interna) e famílias (frequência dos pais e/ou responsáveis nas reuniões programadas dos encontros famílias-escola), além de monitorar diretamente as instituições de ensino (resultados nas avaliações do SAEPE e nas metas do IDEPE). 
Conforme assinala Gentili (1996), para os neoliberais, a ineficiência e a improdutividade da educação pública resultam dos processos de má gestão das redes e instituições de ensino e da ausência de mercado. Dessa forma, estas devem ser reformadas de acordo com os padrões gerenciais privados para atuarem em um quase-mercado educacional. Nessa nova realidade, precisam ser continuamente monitoradas e avaliadas.

O Modelo de Gestão Todos por Pernambuco adota, como foi mencionado, em sua política educacional uma avaliação estandardizada em larga escala, o SAEPE. Essa avaliação foi instituída na política educacional pernambucana no ano de 2000, por meio de uma parceria com o Instituto Nacional de Estudos e Pesquisas Educacionais Anísio Teixeira (INEP) (VALENÇA, 2004) ${ }^{3}$. Desde o princípio o SAEPE tem sido uma avaliação censitária destinada aos estudantes da rede estadual e municipal matriculados nos $3^{\circ}, 5^{\circ}$ e $9^{\circ}$ anos do Ensino Fundamental, assim como do $3^{\circ}$ ano do Ensino Médio nos componentes curriculares de Língua Portuguesa e Matemática ${ }^{4}$ Em 2008, no contexto do Modelo de Gestão Todos por Pernambuco, o SAEPE é reformulado. A partir desse ano o SAEPE é aplicado anualmente com base em uma matriz de referência de avaliação fundamentada na Base Curricular de Pernambuco (BCC-PE) e na Matriz de Referência do Sistema Nacional de Avaliação da Educação Básica (SAEB) (PERNAMBUCO, 2008b). Além disso, adota a Teoria de Resposta ao Item (TRI), o que permitiu a padronização dos resultados de aprendizagem, a medição da proficiência em escalas, a comparabilidade dos resultados entre as instituições de ensino, bem como dessas ao longo do tempo (PERNAMBUCO, 2011a). Essas modificações potencializaram a força do SAEPE como tecnologia gerencial destinada a avaliar e, consequentemente, buscar a eficiência e a eficácia na educação.

O SAEPE consiste em uma avaliação destinada a verificar o desempenho dos estudantes ${ }^{5}$, ou seja, é uma potente tecnologia de controle dos resultados e opera de acordo com a lógica gerencial e de privatização da educação pública. Na verdade, constitui-se no cerne da política de auditoria, monitoramento, avaliação e responsabilização educacional adotada pelo Modelo de

\footnotetext{
${ }^{3}$ A implantação do SAEPE aconteceu no contexto da reforma gerencial do estado, então, apoiada pelo Programa Nacional de Apoio à Modernização da Gestão e do Planejamento dos Estados Brasileiros e do Distrito Federal (PNAGE). Esse movimento de reforma gerencial defendia a constituição de um Estado Avaliador, como concebe Afonso (2000).

${ }^{4}$ Em 2016, passaram a ser avaliados os estudantes do $2^{\circ}$ ano em vez dos matriculados no $3^{\circ}$ ano do Ensino Fundamental (PERNAMBUCO, 2016b).

${ }^{5}$ Progressivamente constata-se o crescimento do número de estudantes avaliados pelo SAEPE. No ano de 2009 a participação dos estudantes no SAEPE em relação ao total previsto para ser avaliado foi de $70 \%$, enquanto no ano de 2015 esse percentual alcançou 92,5\% (PERNAMBUCO, 2015).
} 
Gestão Todos por Pernambuco. Nesse arranjo o SAEPE representa uma tecnologia sine qua non para o funcionamento dessa política educacional, pois se encontra intimamente relacionado com as demais tecnologias empregadas, e sua existência é condição indispensável para o funcionamento dessa política da auditoria. Como esclarece Gentili (1996), nas perspectivas gerenciais pautadas nos princípios do mercado apenas é possível identificar as instituições educacionais que fornecem os melhores resultados por meio dos processos de avaliação de desempenho. Nesse sentido, Freitas (2011, p. 10) afirma que a avaliação de desempenho educacional verticalizada tornou-se uma categoria que orienta o processo de gestão empresarial da educação do princípio ao fim, uma vez que sem “[...] testes, não há responsabilização e meritocracia, teses fundamentais do mercado".

\subsection{Responsabilização, meritocracia e performatividade - caminhos para a competitividade $e$ promoção da "qualidade" da educação}

Os governos que adotam modelos de gestão gerencial, como o Modelo de Gestão Todos por Pernambuco, empregam amplamente tecnologias e discursos de eficiência e eficácia. Buscam resultados quantificáveis que devem ser expressos por meio de indicadores e metas. No campo das políticas educacionais, Ball, Maguire e Braun (2016, p. 24) esclarecem que essa forma de gestão e suas tecnologias operam com um modelo de eficiência que "[...] funciona dentro de uma estrutura disciplinar de metas, referências, tabelas de classificação, de médias e de inspeções que trabalham para oprimir ou deslocar valores e princípios e para subverter as relações sociais".

No caso do Modelo de Gestão Todos por Pernambuco existe uma tecnologia de acompanhamento de resultados quantificáveis por meio de indicadores em sua política educacional. Trata-se do IDEPE, que estabelece os padrões de desempenho, ou seja, as metas que devem ser alcançadas pelas instituições de ensino anualmente. Na lógica dessa gestão, o IDEPE “[...] permite medir anualmente a qualidade da educação” (PERNAMBUCO, 2008a, p. 3). Assim, percebe-se que, segundo a perspectiva gerencial, o IDEPE representa o indicador de qualidade da educação para as instituições educacionais da rede estadual pernambucana.

O IDEPE utiliza uma configuração semelhante à que é adotada pelo Índice de Desenvolvimento da Educação (IDEB). São utilizados dois critérios no cálculo das metas que as instituições de ensino estaduais devem alcançar anualmente: fluxo escolar (aprovação) e desempenho dos estudantes nas avaliações estandardizadas em larga escala. No caso do IDEPE essa avaliação é o SAEPE.

Os modelos de administração gerenciais utilizam, primordialmente, o controle de resultados em vez do controle de processos - presentes nas administrações burocráticas. Assim, os resultados 
são verificados pelo cumprimento ou não das metas estabelecidas antecipadamente. Além disso, esses modelos de administração buscam transferir responsabilidades para os servidores públicos, tornando-os responsáveis pelo alcance de metas, e empregam em muitos casos os contratos de gestão (CLAD, 1999).

O IDEPE é uma tecnologia de regulação e controle de resultados que se efetiva por meio de contratos de gestão para potencializar os processos de responsabilização na educação pública pernambucana. Os contratos de gestão são firmados entre o Governo do Estado, por intermédio do secretário de Educação, e as instituições de ensino. Esse contrato é assinado anualmente, e nele são estabelecidas as metas de desempenho para cada instituição de ensino. Essas metas têm como parâmetro o IDEPE. Nesse contexto, o Termo de Compromisso e Responsabilização é mais uma tecnologia gerencial que opera na política educacional pernambucana e busca formalizar o compromisso das escolas, ou seja, fixa legalmente uma obrigação, a de atingir as metas. Desse modo, constitui-se em um meio para pressionar, regular e estimular o trabalho docente e o desenvolvimento de ações para que as instituições de ensino alcancem as metas pactuadas, ou melhor, os resultados esperados pela gestão gerencial. Sua força é potencializada ao estabelecer que apenas as instituições que são avaliadas pelo SAEPE e que têm as metas calculadas e verificadas pelo IDEPE poderão receber uma bonificação financeira.

Assim, além de estabelecer objetivos e metas a serem alcançadas, busca-se estabelecer a responsabilização das escolas e professores, e isso é concretizado formalmente por meio do Termo de Compromisso e Responsabilização. Nesse contexto, esse termo consiste em, sem dúvida, um mecanismo de accountability típico das administrações públicas que adotam a perspectiva gerencial e que buscam, conforme esclarece Afonso (2009), a imputação de responsabilidades, bem como de sanções aos servidores.

Além disso, considerando-se o contexto educacional criado pelo Modelo de Gestão Todos por Pernambuco, percebe-se uma tendência para estabelecer um ambiente permeado pela performatividade. Segundo esclarece Ball (2005), a performatividade é uma tecnologia que emprega mecanismos de visibilidade e exposição pública, bem como utiliza os processos de mensuração, os julgamentos e as comparações, as classificações e os rankings como meio de regulação. É dessa forma que as divulgações dos resultados das escolas no SAEPE/IDEPE na mídia e nos meios oficiais públicos de divulgação, bem como a constituição dos rankings com as 
melhores e piores escolas podem ser compreendidas ${ }^{6}$. Além disso, para Ball (2014), a escolha de escolas é uma das soluções propostas pelo modelo de educação global para solucionar os problemas e alcançar a "qualidade" na educação. Esse processo é estimulado pela exposição pública dos resultados das escolas nas avaliações externas e indicadores educacionais.

Em tal contexto, a performatividade estabelece uma vigilância permanente, uma espécie de panoptismo que impõe uma poderosa carga emocional aos professores, deixando-os inseguros e com o sentimento de não saber se estão fazendo o trabalho de forma correta, de modo suficiente e tão bem quanto os demais profissionais (BALL, 2005).

De acordo com Ball (2014), o processo de escolha de escolas é uma ideia central defendida pelos atores que buscam influenciar a implementação de políticas educacionais norteadas pelos princípios do mercado. Nesse contexto, a divulgação pública dos resultados das instituições nas avaliações de desempenho educacional e a constituição de rankings de escolas são primordiais, pois, de acordo com Afonso (2000), estimulam os mecanismos de competição administrada e a constituição dos quase-mercados, extinguindo, consequentemente, as fronteiras entre o público e o privado, bem como transformando a essência dos direitos sociais. Nessa lógica, a educação passa a ser concebida como mercadoria ou produto.

O Modelo de Gestão Todos por Pernambuco emprega ainda em sua política educacional uma tecnologia que utiliza o recurso do incentivo financeiro de acordo com o mérito, o BDE, que foi instituído por meio da Lei 13.486, de 1 de julho de 2008 (PERNAMBUCO, 2008c) e constituise em uma poderosa tecnologia fundamentada na meritocracia, que estabelece um mecanismo de premiação-punição para os servidores públicos em função dos resultados alcançados pelas instituições de ensino.

O Modelo de Gestão Todos por Pernambuco afirma que o BDE é "[...] um incentivo para promover a qualidade do ensino e valorizar a remuneração dos profissionais da educação, mas não faz parte do salário mensal dos servidores" (PERNAMBUCO, 2008a, p. 7). Na verdade, o BDE é uma tecnologia para motivar e incentivar os docentes a trabalharem para promover a "qualidade" da educação, ou seja, desenvolver um trabalho específico para as instituições de ensino alcançarem

\footnotetext{
${ }^{6}$ Exemplos disso podem ser verificados em: JC Online. Alunos e professores já podem consultar notas do Idepe. Jornal do Comércio On Line. 10 de jul. de 2012. Disponível em: <http://jconline.ne10.uol.com.br/canal/cidades/educacao/ noticia/ 2012/07/10/alunos-e-professores-ja-podem-consultar-notas-do-idepe-48604.php>. Acesso em: 01 de abri. 2017; PERNAMBUCO. Balanço da Educação 2016. Recife, 2016c. Disponível em:< http://www.educacao.pe.gov.br/ portal/upload/galeria/12289/BALAN\%C3\%870\%20DA\%20EDUCA\%C3\%87\%C3\%830\%202016(1).pdf>. Acesso em: 10 jun. 2017.
} 
tanto as metas estabelecidas pelo IDEPE, no Termo de Compromisso e Responsabilização, como as do IDEB. Essa é a qualidade da educação esperada na perspectiva da administração gerencial do Modelo de Gestão Todos por Pernambuco. Além disso, o BDE não promove uma verdadeira valorização dos profissionais da rede estadual de educação pernambucana, uma vez que não faz parte do seu salário recebido mensalmente.

Conforme esclarece Freitas (2012), estudos científicos, como, por exemplo, o realizado por Hout e Elliott $(2011)^{7}$, constatam que políticas educacionais fundamentadas em meritocracia não produzem resultados significativos. Ou seja, esse modelo de política educacional não apresenta evidências empíricas de que seja capaz de oferecer boa educação. Assim, segundo esse autor, empregar recursos para promover a meritocracia na educação, além de ocasionar o desperdício dos recursos financeiros, é uma prática não fundamentada na ética que deve reger a coisa pública.

Esse modelo de política educacional fundamentada em avaliações estandardizadas em larga escala, metas e pagamento de acordo com o mérito/resultado, estimula a constituição de quasemercados e os processos de competição entre as instituições de ensino para alcançar as melhores posições nos rankings. Esse fato altera as concepções da educação pública e permite diferenciações e competitividade como requisitos para alcançar a qualidade (SOUSA; OLIVEIRA, 2003). Essa é a lógica do mercado e do darwinismo social atravessando as políticas públicas (GENTILI, 1996).

\section{CONSIDERAÇÕES FINAIS}

Com a implantação do Modelo de Gestão Todos por Pernambuco, a partir do ano de 2007, constatam-se amplas e profundas repercussões das políticas neoliberais e gerenciais no âmbito das políticas educacionais na rede de educação do estado de Pernambuco. Uma das ações mais importantes para assegurar o gerencialismo e sua defesa de eficiência pautada no controle dos resultados foi a implementação de uma política de avaliação de desempenho educacional que opera de forma integrada e, com interconexões, um conjunto de tecnologias. Essa estratégia contribuiu para introduzir a lógica do mercado na educação pública pernambucana, em que um determinado padrão de "qualidade" da educação é alcançado, sobretudo, pela competição, meritocracia e responsabilização, pois, como esclarece Ball (2014), o neoliberalismo acredita que pode obter sucesso onde o Estado e os governos falharam.

\footnotetext{
${ }^{7}$ HOUT, M.; ELLIOTT, S.V. Incentives and test-based accountability in education. Washington, DC: National Academy of Sciences, 2011.
} 
A reforma educacional defendida pelo mercado e implementada pelo Modelo de Gestão Todos por Pernambuco não é capaz de garantir boa educação, uma formação humana integral nem uma educação como direito social. Essa afirmação se assenta na certeza de que oferecer boa educação não significa implantar gestões gerenciais, tecnologias do mercado, nem focar o processo de ensino-aprendizagem dos componentes curriculares de Língua Portuguesa (ler e escrever) e Matemática (operações básicas). Tampouco se resume em desenvolver competências básicas, capacidade para resolver problemas e habilidades para se adaptar a um mercado em constante mudança - aprender a aprender. Na verdade, esse modelo de educação atende às necessidades de mão de obra do mercado e aos interesses de acumulação do capital no cenário da globalização financeira.

De acordo com Freitas (2013), estudos apontam que países que utilizaram o modelo de educação gerencial focada em resultados não conseguiram assegurar boa educação nem resultados relevantes, nem mesmo se observados os seus próprios padrões. Segundo esse autor a lei No Child Left Behind (NCLB) nos Estados Unidos é um bom exemplo. Por sua vez, estudos realizados no campo das políticas educacionais, como os de Casassus (2002) e Carnoy (2009), demonstram que uma boa educação se encontra relacionada com um conjunto de variáveis internas e externas às instituições de ensino que apresentam relações complexas, interagem e se influenciam mutuamente, como a promoção da saúde; a redução da violência e das desigualdades sociais; a promoção da igualdade de renda; o combate aos processos de segregação social e educacional; o compartilhamento com as famílias da responsabilidade pela acompanhamento e educação dos filhos; a garantia de frequência dos estudantes; a adoção de processos de recrutamento dos melhores estudantes para o magistério; número reduzido de estudantes por sala de aula; formações, inicial e continuada, adequadas para os docentes; autonomia docente; prédios escolares, bibliotecas e materiais didáticos apropriados; ambiente educacional favorável ao processo de ensinoaprendizagem; entre outros.

Diante dessa lista de variáveis, segundo Ravitch (2011), não existem respostas e soluções rápidas para se assegurar boa educação, como as que são defendidas pelo mercado e pelo gerencialismo. Além do mais, as políticas gerenciais na educação produzem graves, perversas e danosas repercussões no cotidiano escolar e, mormente, sobre os seus atores fundamentais, os professores e estudantes, como evidenciam as pesquisas realizadas. Para Freitas (2012, 2013, 2014), entre os principais efeitos dessas políticas estão os processos de segregação e exclusão nas escolas, com os estudantes mais "fracos" sendo os mais prejudicados; o estreitamente curricular e a preparação para as avaliações externas, focando o trabalho pedagógico, principalmente, nos 
componentes curriculares de Língua Portuguesa e Matemática; as fraudes e estratégias para burlar o sistema, como a realização de processos específicos de preparação para as avaliações externas; o aniquilamento das atividades colaborativas e das relações multilaterais vivenciadas por professores e estudantes; o estímulo a desqualificação e desprofissionalização docente; assim como a destruição moral dos professores pela exposição pública e inadequada das instituições educacionais nos rankings publicados pela grande mídia.

Nesse sentido, Carnoy (2009, p. 73) afirma que existem fortes evidências de que as políticas educacionais gerenciais embasadas nos princípios do mercado "[...] podem ser incompatíveis com a ideia de maior benefício para os indivíduos". Por isso, inúmeros educadores e pesquisadores têm-se posicionado contra esse modelo de política educacional. 


\section{REFERÊNCIAS}

AFONSO, A. J. Avaliação Educacional: regulação e emancipação: para uma sociologia das políticas avaliativas contemporâneas. São Paulo: Cortez, 2000.

Políticas avaliativas e accountability em educação: subsídios para um debate ibero-americano. Sísifo: Revista de Ciências da Educação, Lisboa, n. 09, p. 57-70, mai./ago. 2009. Disponível em:<https://www.yumpu.com/pt/ document/view/14840135/políticas-avaliativas-e-accountability-em-educacao-sisifo>. Acesso em: 16 jun. 2017.

ANDRADE, M.Â.C. A implementação do Sistema de Informações da Educação de Pernambuco e sua aplicação para melhoria da gestão escolar. 216 f. Dissertação (Mestrado em Gestão e Avaliação da Educação Pública) Universidade Federal de Juiz de Fora, Juiz de Fora, 2014.

BALL, S. J. Profissionalismo, gerencialismo e performatividade. Cad. de Pesqui., São Paulo, v. 35, n. 126, p. 539-564, set./dez. 2005. Disponível em: < http://www.scielo.br/pdf/cp/v35n126/a02n126.pdf>. Acesso em: 10 jun. 2017.

Educação Global S.A.: novas redes políticas e o imaginário neoliberal. Ponta Grossa: UEPG, 2014.

; MAGUIRE, M.; BRAUN, A. Como as escolas fazem as políticas. Ponta Grossa: UEPG, 2016.

BOWE, R.; BALL, S. J.; GOLD, A. Reforming education and changing schools: case studies in policy sociology. London: Routledge, 1992.

BRESSER-PEREIRA, L. C. Reforma da nova gestão pública: agora na agenda da América Latina, no entanto... Revista do Servidor Público, ano 53, n. 1, jan./mar. 2002. Disponível em: < https://revista.enap.gov.br/index.php/RSP/article/ view/278/284>. Acesso em: 24 maio. 2013.

; SPINK, P. K. (Orgs.). Reforma do Estado e administração pública gerencial. 7. ed. Rio de Janeiro: Editora da FGV, 2006.

CAMPOS, V. F. TQC - Controle da Qualidade Total. Nova Lima: INDG Tecnologias e Serviços Ltda, 2004.

CARNOY, M. A vantagem acadêmica de Cuba: por que seus alunos vão melhor na escola. São Paulo: Ediouro, 2009.

CASASSUS, J. A escola e a desigualdade. Brasília: Plano Editora, 2002.

CLAD - Centro Latino Americano de Administração para o Desenvolvimento. Uma Nova Gestão Pública para América Latina. Brasília, Revista do Serviço Público, ano 50, n. 1, jan.-mar. 1999. Disponível em: < http://seer.enap.gov.br/ index. php/ RSP/ article/view/343/349>. Acesso em: 26 de fev. 2017.

CRUZ, M.S.M.; MARINI, C.; LEMOS, M. Modelo de Gestão Todos por Pernambuco: características e avanços. In: Congresso CONSAD de Gestão Pública, 7, 2014, Brasília. Anais eletrônicos... Disponível em: < http://banco.consad. org.br/bitstream/123456789/1122/1/C7_PP_MODELO\%20DE\%20GESTÃO\%20TODOS\%20POR\%20PERNAMBUC O.pdf>. Acesso em: 21 de abr. 2017.

FREITAS, L. C. de. Responsabilização, meritocracia e privatização: conseguiremos escapar ao neotecnicismo? In: Seminário de Educação Brasileira, 3. Simpósio PNE - Diretrizes para Avaliação e Regulação da Educação Nacional. Campinas: CEDES, 2011. Disponível em <https://docs.google.com/viewer?a=v\&pid=sites\&srcid=ZGVmYXV sdGRvbWFpbnxhbG1hY2VucG5wfGd4OjZjZTA0MTdkNGJhMGEyMzY> 18 jun. 2016.

Os reformadores empresariais da educação: da desmoralização do magistério à destruição do sistema público de educação. Educ. Soc., Campinas, v. 33, n. 119, p. 379-404, abr.-jun. 2012. Disponível em < http://www.scielo.br/ scielo.php?p id=S0101-73302012000200004\&script=sci_abstract\&tlng=pt >. Acesso em: 18 jun. 2016.

Caminhos da Avaliação de Sistemas Educacionais no Brasil: o embate entre a cultura da auditoria e a cultura da avaliação. In BAUER, Adriana; GATTI, Bernadete A. 25 anos de avaliação de sistemas educacionais no Brasil: implicações nas redes de ensino, no currículo e na formação de professores. vol. 2, Florianópolis: Insular, 2013.

Os reformadores empresariais da educação e a disputa pelo controle do processo pedagógico na escola. Educ. Soc., Campinas, v. 35, n. 129, p. 1085-1114, out./dez. 2014. Disponível em < http://www.scielo.br/pdf/es/v35n129/ 0101- 7330-es-35-129-01085.pdf >. Acesso em: 18 jun. 2016

GENTILI, P. Neoliberalismo e educação: manual do usuário. In: GENTILI, P.; SILVA, T. T. (Orgs.). Escola S. A. quem ganha e quem perde no mercado educacional no neoliberalismo. Brasília: CNTE, 1996. 
GIDDENS, A. A terceira via: reflexões sobre o impasse político atual e o futuro da social-democracia. 5. ed. Rio de Janeiro: 2005.

MARINI, C.; MARTINS, H. F. Todos por Pernambuco em tempos de governança: conquistas e desafios. Recife: Secretaria de Planejamento e Gestão do Governo do Estado de Pernambuco; Brasília: Instituto Publix, 2014. Disponível em: < http://www.seplag.pe.gov.br/web/tppe/docmg-documentacao-do-modelo-de-gestao\#\&panel1-1>. Acesso em: 17 de mar. 2017.

PERNAMBUCO. Nota Técnica: a avaliação das escolas estaduais e o bônus de desempenho educacional - BDE. Recife: Secretaria de Educação, 2008a. Disponível em: <http://www.educacao.pe.gov.br/diretorio/pmg2/nota_tecnica_ idepe.pdf>. Acesso em: 26 de nov. 2016.

Boletim Pedagógico de Avaliação da Educação: SAEPE - 2008. v. 1, jan./dez. 2008b. Disponível em: < http://www.saepe.caedufjf.net/wp-content/uploads/2016/05/BoletimPedagocico_LP_3AnoEMSAEPE_2008.pdf>. Acesso em: 26 de nov. 2016.

. Lei 13.486, de 1 de julho de 2008. Institui o Bônus de Desempenho Educacional - BDE, no âmbito do Estado de Pernambuco. Diário Oficial [do] Estado de Pernambuco, Poder Executivo, Recife, PE, 02 jul. 2008c. Seção 1, p. 6. Disponível em: < http://legis.alepe.pe.gov.br/arquivoTexto.aspx?tiponorma=1\&numero=13486\&complemento= 0\&ano=2008\&tipo=TEXTOATUALIZADO $>$ Acesso em: 26 de nov. 2016.

Revista do Sistema SAEPE. v. 1, jan./dez. 2011a. Disponível em: <http://www.saepe.caedufjf.net/wpcontent/uploads/2016/05/SAEPE_Boletim_v1_2011.pdf>. Acesso em: 10 de jun. 2017.

Portaria SE 4.636, de 05 de julho de 2011. Constituir o Comitê Gestor do SIEPE. Diário Oficial [do] Estado, Poder Executivo, Recife, PE, 06 jul. 2011b. Seção 1, p. 13. Disponível em: < http://200.238.105.211/cadernos/2011/ 20110706/1-PoderExecutivo/PoderExecutivo(20110706).pdf>. Acesso em: 26 de mar. 2017.

Poder Executivo. Decreto 39.336, de 25 de abril de 2013. Estabelece o Valor Público como objetivo dos Programas de Estado, fixa diretrizes para a Gestão por Resultados, e estabelece a execução dos Pactos de Resultados no âmbito do Poder Executivo Estadual. Diário Oficial [do] Estado de Pernambuco, Poder Executivo, Recife, PE, 26 abr. 2013. Seção 1, p. 6. Disponível em: <http://legis.alepe.pe.gov.br/arquivoTexto.aspx?tiponorma=6\&numero $=39336 \&$ complemento=0\&ano=2013\&tipo=>. Acesso em: 26 de mar. 2017.

Relatório de Gestão Social 2014 (2 Quadrimestre). Recife, 2014. Disponível em: <http://www.seplag.

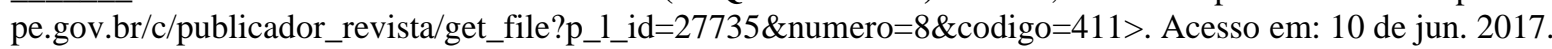

Revista do Sistema de Avaliação: SAEPE 2015. Disponível em: < http://www.saepe.caedufjf.net/wpcontent/uploads/2016/05/PE-SAEPE-2015-RS-RE-WEB2.pdf>. Acesso em: 10 de jun. 2017.

Relatório Anual de Ação do Governo 2016. Recife, 2016a. Disponível em: < http://www.seplag. pe.gov.br/c/publicador_revista/get_file?p_1_id=27735\&numero=10\&codigo=410>. Acesso em: 22 de jul. 2017.

Revista do Sistema: SAEPE - 2016. v. 2, jan./dez., 2016b. Disponível em: < http://www.saepe.caedufjf.net/ wp-content/uploads/2017/03/PE-SAEPE-2016-RS-MR-WEB.pdf>. Acesso em: 18 jun. 2016.

PSB. Programa de Governo da Frente Popular de Pernambuco: Um novo Pernambuco. Pernambuco, 2006. Disponível em: <http://www.seplag.pe.gov.br/web/tppe/todos-por-pe-programas-de-governo>. Acesso em: 26 de abr. 2017.

RAVITCH, D. Vida e morte do grande sistema escolar americano: como os testes padronizados e o modelo de mercado ameaçam a educação. Porto Alegre: Sulina, 2011.

SPENDOLINI, M. J. Benchmarking. São Paulo: Makron Books, 1993.

SOUSA, S. M. Z. L. ___ _ OLIVEIRA, R. P. Políticas de avaliação da educação e quase mercado no Brasil. Educ. Soc., Campinas, vol. 24, n. 84, p. 873-895, set. 2003. Disponível em: < http://www.scielo.br/scielo.php?pid=S0101$73302003000300007 \&$ script=sci_abstract\&tlng=pt>. Acessos em 10 jun. 2017.

VALENÇA, M. E. Sistema de Avaliação Educacional de Pernambuco - SAEPE (2000-2002). In: BONAMINO, Alícia, BESSA, Nícia; FRANCO, Creso (Orgs.). Avaliação da Educação Básica: pesquisa e gestão. Rio de Janeiro: Editora da PUC-Rio; São Paulo: Loyola, 2004.

WERKEMA, M. C. C. As ferramentas da qualidade no gerenciamento de processos. Belo Horizonte: Editora de Desenvolvimento Gerencial, 1995. 


\section{RESUMO}

Neste artigo, investiga-se a política educacional do Modelo de Gestão Todos por Pernambuco, considerandose sua perspectiva neoliberal e gerencial e focando-se, especificamente, a sua política de avaliação de desempenho educacional. O estudo desenvolve-se por meio de pesquisa bibliográfica e documental e apoia-se no referencial teórico-metodológico da Abordagem do Ciclo de Políticas (BOWE; BALL; GOLD, 1992). Constata-se no estudo que a sua política de avaliação de desempenho educacional articula inúmeras tecnologias para promover processos de responsabilização, meritocracia e performatividade, como meios de garantir uma educação de "qualidade".

Palavras-chaves: Gerencialismo. Políticas educacionais. Avaliação de desempenho educacional.

\section{EVALUATION, MERITOCRACY, AND PERFORMATIVITY: AN ANALYSIS OF THE EDUCATIONAL POLICY OF PERNAMBUCO}

\section{ABSTRACT}

This article investigates the educational policy of the Management Model All by Pernambuco, considering its neoliberal perspective and managerial skills and focusing, specifically, its policy of evaluation of educational performance. The study develops by means of a bibliographic and documentary research and supports the theoretical-methodological Approach of the Cycle of Policies (BOWE; BALL; GOLD, 1992). It is noted in the study that its policy of evaluation of educational performance articulates several technologies to promote accountability processes, meritocracy, and performativity, as a means of ensuring an education of "quality".

Keywords: Managerialism. Educational policies. Evaluation of educational performance.

\section{EVALUACIÓN, MERITOCRACIA Y PERFORMACIÓN: UN ANÁLISIS DE LA POLÍTICA EDUCACIONAL PERNAMBUCANA}

\section{RESUMEN}

En este artículo, se investiga la política educativa del Modelo de Gestión Todos por Pernambuco, considerando su perspectiva neoliberal y las destrezas gerenciales y centrándose, específicamente su política de evaluación de desempeño educativo. El estudio se desarrolla por medio de una investigación bibliográfica y documental y se apoya en el referencial teórico-metodológico del Enfoque del Ciclo de Políticas (BOWE, BALL, GOLD, 1992). Se constata en el estudio que su política de evaluación de desempeño educativo articula innumerables tecnologías para promover procesos de responsabilización, meritocracia y performatividad, como medios de asegurar una educación de calidad.

Palabras claves: Gerencialismo. Políticas educativas. Evaluación de desempeño educativo. 